\title{
Understanding corrosion of flexible pipes at subsea oil and gas wells
}

\author{
By Melissae Fellet \\ Advisor: Rolf Nyborg
}

$F_{\mathrm{B}}^{\mathrm{l}}$ lexible pipes installed at two offshore natural gas wells in Brazil's pre-salt fields recently ruptured after only a few years of operation. These pipes were expected to last more than 20 years, so Petrobras, the company developing the fields, investigated the cause of the failure. They discovered damage to the pipes' outer cover and found corroded steel armor wires in the pipes. Executives were surprised to learn that high concentrations of carbon dioxide contributed to the corrosion and eventual ruptured pipes. Failures, while infrequent relative to the thousands of flexible pipes in operation, have also occurred in at least four flexible risers connecting floating production vessels to subsea wells off the coasts of Norway and Africa.

When flexible pipes were first introduced 30 years ago, it was thought that the interior of the pipes remained dry and noncorrosive. However, engineers now know that the unique environment that traps water vapor and carbon dioxide between layers of steel inside the pipe contributes to corrosion-even when its external cover is undamaged. Producers are beginning to use corrosion-resistant composite flexible pipes for subsea flow lines at deep wells. Companies are also testing and developing hybrid systems that combine steel and composite pipes to maximize the benefits of both systems.

With oil and gas reserves in shallow waters running dry, producers are turning to fields in deep and ultra-deep waters off the coasts of Brazil, Norway, Angola, and the United States. Bringing fluids through 3000 meters of water to the surface poses new challenges for well operators: production fluids with increased temperatures and pressures that challenge welds; increased carbon dioxide - and sometimes hydrogen sulfide - that scour and weaken steel; deep ocean water pushing on pipes with increased pressures; and currents trying to drag pipes through the water. "Any one of those things would be manageable," said Martin Jones, chief executive officer at Magma Global Ltd., a company that produces composite flexible pipe. "But the high temperatures, pressures, and corrosive fluids together make it very difficult for traditional materials."

The industry's standard steel-reinforced flexible pipe starts with a corrugated liner made by interlocking S-shaped pieces of duplex stainless steel or high-strength steel alloyed with nickel or molybdenum. To make this structure gas- and hydrocarbon-tight, a thermoplastic polymer liner, typically polyamide, poly(vinylidine) fluoride (PVDF), or high-density polyethylene (HDPE), is extruded over the steel carcass. Then, layers of high- strength carbon steel wire are wound helically or circumferentially around the pipe. These armor layers reinforce the pipe to handle stress from pressure inside and outside the pipe, as well as tensile stresses from subsurface currents. A slippery polymer tape, about a millimeter thick, separates each layer of wound armor wire and allows the metal layers to move freely on top of each other. After a pipe has been wound with enough steel reinforcement layers needed for a particular site, it is covered with a tough thermoplastic polymer, such as HDPE. Flexible pipes that need to withstand high temperature, pressure, and tidal stresses in ultra-deep water can have as many as 19 layers.

The most common damage to these pipes is a ruptured outer cover, often through accidents in handling or a collision with a ship. This allows oxygenated seawater to flood the interior layers of a pipe, destroying the steel armor wires at least 10 times faster than during normal operation. But after dissecting pipes that have ruptured in the field, researchers have learned that corrosion resulting from such a collision is caused by seawater interacting with carbon dioxide that originally seeped into the pipe from the production fluid, not oxygen gas introduced following an accident.

Because of this mechanism of internal corrosion, researchers have even found corroded wires in undamaged flexible pipes examined after a decade of operation. Academic and industrial researchers in Norway, Brazil, and the United Kingdom are studying the details of this corrosive process using computer models and experiments that replicate conditions in deep wells.

Corrosion in undamaged flexible pipes begins at the polymer liner surrounding the innermost steel carcass of a flexible pipe. Since this liner is in contact with fluid from the well bore, carbon dioxide and water vapor from the production fluid seep through it. These gases can be detected in gas vented from the pipe annulus - the space between the inner and outer polymer coverings.

Inside the annulus, water vapor condenses along the layers of steel armor wire. Carbon dioxide dissolved in that water produces carbonic acid, $\mathrm{H}_{2} \mathrm{CO}_{3}$, which reacts with iron in the steel to generate iron(II) and carbonate ions. Because there is a high surface area of exposed steel compared to the volume of water covering it, these dissolved ions quickly react to form a precipitate of iron carbonate.

To study this process, researchers at the Institute for Energy Technology in Norway developed a system to control the concentration of dissolved iron and carbonate ions around a strip of steel armor wire. First, they submerged steel wool in water and bubbled carbon dioxide through the solution to create dissolved corrosion 
products. Next, the researchers pumped the solution of dissolved iron and carbonate ions into a tank containing strips of suspended armor wire.

A coating of iron carbonate crystals formed on the armor wire within hours to days. The high amount of dissolved iron kept the coating intact, slowing steel corrosion caused by carbon dioxide to an acceptable rate of $0.01 \mathrm{~mm}$ per year.

To study how oxygen influences armor wires exposed to carbon dioxide corrosion, researchers bubbled oxygen gas into a tank containing armor wire covered with a layer of iron carbonate. They examined cross sections of the steel samples using scanning electron microscopy and found pores in the

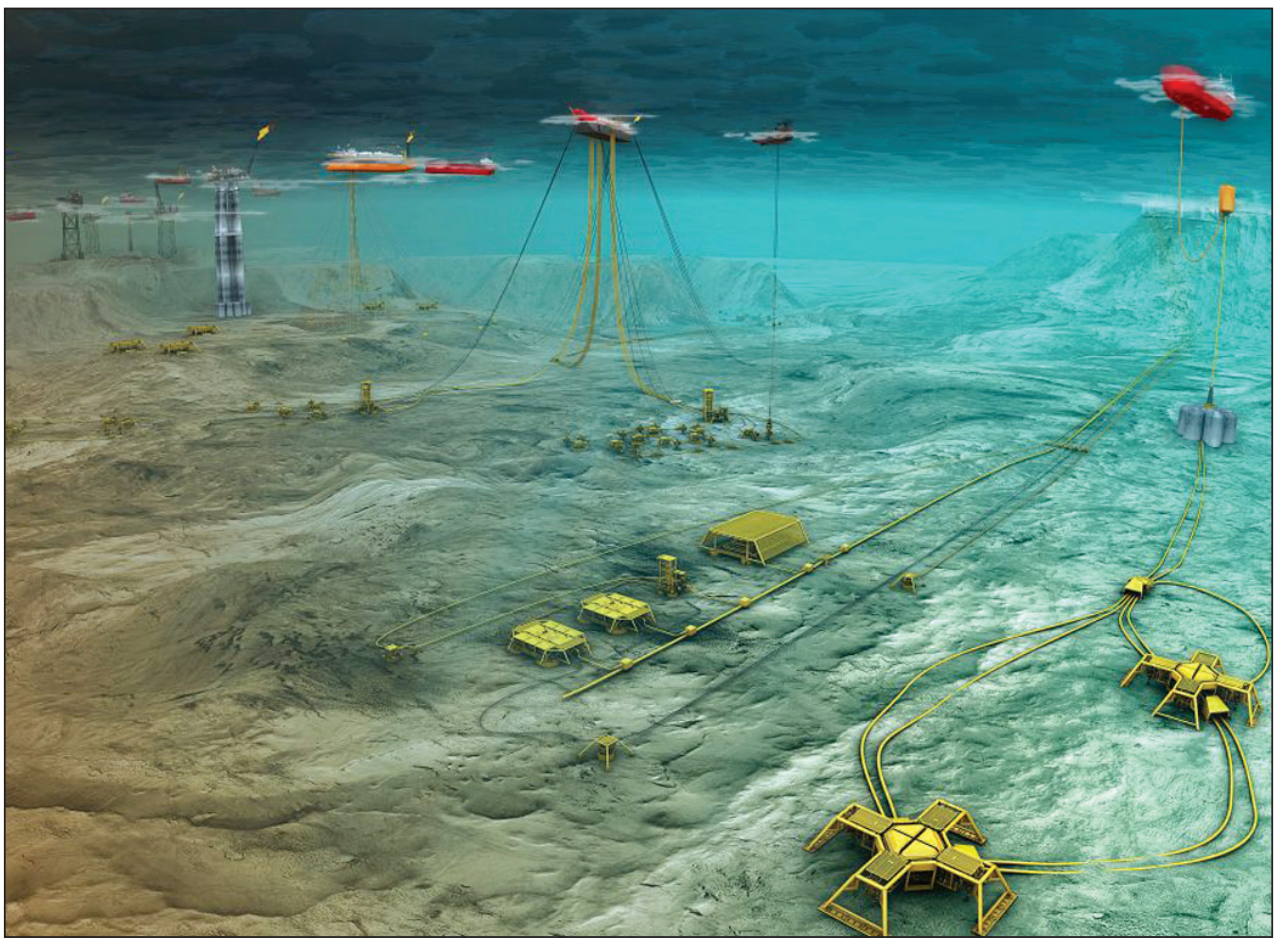

Vision of future subsea oil and gas production. (C) TechnipFMC. iron carbonate layer protecting the steel surface. As oxy-

gen reacted with iron in the water surrounding the steel, the iron carbonate coating dissolved to replace the soluble iron ions. The presence of oxygen, itself a corrosive agent, increased the rate of carbon dioxide corrosion of the steel armor wires.

Carbon dioxide corrosion can generate pits in the surface of the wire. With repeated stress, cracks might form from these pits and cause the steel wires to snap. Research to refine knowledge about the detailed mechanisms of carbon dioxide-induced corrosion of steel armor wires can help well operators better predict how long a flexible pipe will safely last.

However, there is a way to eliminate stress-induced corrosion cracking: Eliminate the steel from flexible pipes. Companies such as Airborne Oil \& Gas and Magma produce flexible pipes for the oil and gas industry by winding layers of composite reinforced with glass or carbon fibers around a polymer liner. Each layer of the thermoplastic composite is fused to the one below it. Composite pipes are much lighter than steel flexible pipes, so operators can use simpler, less expensive equipment to install them.

Airborne tailors the material selection to produce pipes that can handle temperatures, pressures, and chemical composition of production fluids at a given site. Currently, the company is qualifying pipes reinforced with a carbon fiber/PVDF composite for high-temperature and pressure applications, along with providing the highest chemical resistance and lowest permeability of their products.

Magma produces thermoplastic flexible pipes using poly(ether ether ketone) (PEEK) reinforced with glass and carbon fibers. PEEK's advantage is that it is about 100 times less permeable to carbon dioxide, hydrogen sulfide, and acids than other polymers used for composite pipes, said Jones. The pipes can be used at depths of 3000 meters.
However, producers are slow to switch to composite pipes because the oil and gas industry can be wary of trying new technologies. In 2014, Airborne and Magma, along with polymer companies, oil and gas producers, and installation contractors, among others, developed recommended practices for the design and quality testing of thermoplastic pipes. These guidelines specify stress and strength testing to prevent cracks and delamination, fluid absorption and permeability tests to prevent pipe degradation, and tests of thermal stability to prevent deformations that could weaken joints and end fittings. The document provides industry with a tool for reassurance, which should help increase the use of thermoplastic flexible pipes, said Geoff Small, market technology manager at Victrex, which supplies Magma with PEEK. The pipes are beginning to be used in various locations around the world as flow and intervention lines connecting subsea components.

Now, the race is on to make a composite riser. Additional layers of laminate provide a pipe that can accommodate the forces and loads on a riser dangling from a floating platform to the seafloor, but then the thicker pipe loses flexibility. Magma's solution comes from a collaboration with TechnipFMC, a supplier of traditional steel-reinforced flexible pipe. The companies are building a hybrid pipe lined with Magma's low-permeability PEEK composite and surrounded by steel armor wires. The pipe is currently being qualified for use, said Jones. Airborne is also in the process of qualifying their carbon fiber/PVDF pipes for use in fully composite risers. The qualification process involves extensive testing of the laminate and then the pipes on both small and large scales. 